
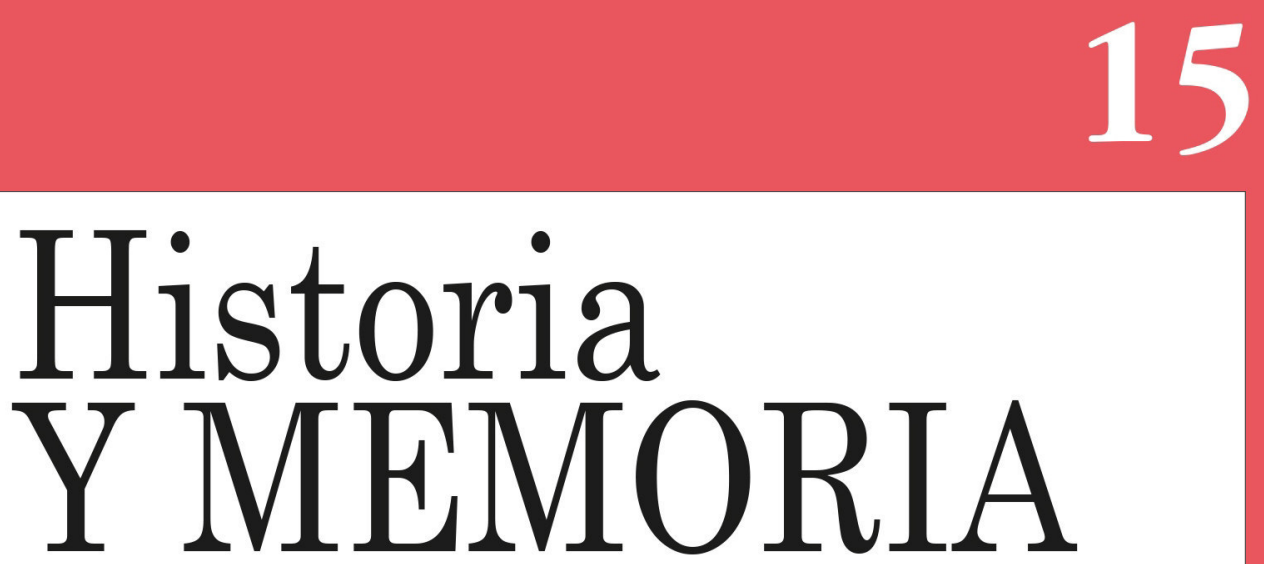

ISSN: 2027-5137 Julio - Diciembre, Año 2017 - Tunja, Colombia

Migración española hacia América desde la perspectiva de la Cartilla del Emigrante (1910)

https://doi.org/10.19053/20275137.n15.2017.5594

Martín Pérez Acevedo

orcid.org/0000-0002-5536-2581

Páginas: 169-201

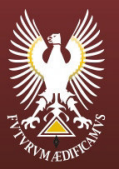




\title{
Migración española hacia América desde la perspectiva de la Cartilla del Emigrante (1910)*
}

\author{
Martín Pérez Acevedo ${ }^{1}$ \\ Instituto de Investigaciones Históricas UMSNH - México
}

Recepción: 05/11/2016

Evaluación: 29/03/2017

Aprobación: 05/06/2017

Artículo de Investigación e Innovación.

https://doi.org/10.19053/20275137.n15.2017.5594

\section{Resumen}

En 1910 la publicación en Madrid de la Cartilla del Emigrante, por parte de la Unión Ibero-Americana, vino a responder al esfuerzo por encausar e informar a aquellos españoles que decidían migrar a América, con la finalidad de mejorar sus condiciones de vida. En efecto, a lo largo de las páginas de su obra tanto Jesús María Rísquez como Melchor Ordóñez, en su condición de autores así como en su calidad de médico y catedrático respectivamente, señalaron las particularidades que suponía el transvase tanto legal como ilegal.

De esta manera se ponderaba el conocimiento del marco migratorio de ambos lados del Atlántico, lo que en teoría

\footnotetext{
* [Dedicatoria: A Olivia Griselda: por ser parte del trayecto en todas las circunstancias]. [El autor agradece los comentarios y puntualizaciones de los dictaminadores de este trabajo. Su sincero reconocimiento por la generosidad en compartir y sugerir materiales].

1 Doctor en Humanidades (Universidad Jaume I - España), Profesor-investigador Titular del Instituto de Investigaciones Históricas de la Universidad Michoacana de San Nicolás de Hidalgo. Investigador del grupo: "Cuerpo Académico 229. Economía, sociedad, educación y cultura en México y América Latina». Líneas de investigación: historia económica y social de México siglos XIX y XX, historia de las relaciones internacionales de México siglo XX e historia de la presencia extranjera en México y América Latina. Autor de Extranjeros y revolución en México. Impacto $y$ consecuencias entre la población europea, 1910-1920 (Morelia: UMSNH, Instituto de Investigaciones Históricas, Morevallado editores, 2016). $\bowtie$ mpacevedo63@yahoo. com.mx (i) orcid.org/0000-0002-5536-2581
} 
garantizaría el ejercicio pleno de derechos y obligaciones. A juicio de Rísquez y Ordoñez era fundamental advertir sobre las líneas navieras y las condiciones del viaje, sobre todo de cara al pago del viaje y el escenario médico sanitario en el que se realizaría la travesía. Las potencialidades y características físicas de los países de destino en el continente americano fueron igualmente señaladas, lo que unido al perfil laboral del migrante español le facilitarían su inserción. Por lo tanto, el cumplimiento en mayor medida de los preceptos de la Cartilla del Emigrante, permitiría perfilar al migrante español como un elemento activo en su devenir cotidiano y, por ende, como una expresión individual y colectiva del hispanismo en América.

Palabras clave: migración, españoles, legislación, hispanismo.

\section{Spanish Migration towards America from the Perspective of the Emigrant's Handbook [Cartilla del Emigrante] (1910)}

\section{Summary}

The publication of the Emigrant's Handbook [Cartilla del Emigrante] in 1910, by the Ibero-American Union responded to the effort of directing and informing Spanish citizens who wished to migrate to America, in order to improve their life conditions. In this work, its authors Jesús María Rísquez, medical doctor, and Melchor Ordoñez, teacher, explained the particularities represented by both the legal and illegal transfer.

In this way, knowledge of the migratory framework on both sides of the Atlantic was pondered; which in theory guaranteed full exercise of rights and obligations. In the opinion of Rísquez and Ordoñez, it was fundamental to warn about the shipping lines and travel conditions, especially with regards to trip payment and the sanitary medical scenery of the journey. The potentialities and physical characteristics of destination countries in the American continent were equally pointed out, as well as the work profile of the Spanish 
migrant, which would allow easier insertion. For this reason, fulfillment of the precepts of the Emigrant's Handbook, would allow the construction of a profile of the Spanish migrant as an active element in the daily flow of life, and therefore as an individual and collective expression of Hispanism in America.

Key Words: Migration, Spaniards, Legislation, Hispanism.

\section{Migration espagnole vers le continent américain selon la Cartilla del Emigrante (1910)}

\section{Résumé}

En 1910 la parution à Madrid de la Cartilla del Emigrante chez l'Union Ibéro-Americana répond à l'effort de guider et de renseigner les Espagnols qui, dans l'espoir d'améliorer leur vie, décident de migrer vers le continent américain. En effet, tout au long des pages, le médecin Jesús María Rísquez et le professeur universitaire Melchor Ordóñez, auteurs de l'ouvrage, signalent les particularités d'un tel voyage, qu'il soit légal ou illégal.

Ainsi, l'examen minutieux de la législation migratoire devait garantir au voyageur le plein exercice de ses droits et devoirs. Selon Rísquez et Ordoñez, il était essentiel, en outre, de connaître les compagnies de navigation transatlantiques et les conditions du voyage, puisqu'il fallait payer celui-ci et faire face aux conditions sanitaires de la traversée. Les atouts et les caractéristiques physiques des pays d'accueil ont été également signalés, ce qui, allié au profil en tant que travailleur du migrant espagnol, devait rendre plus aisée l'incorporation de celui-ci dans la nouvelle société. Le respect, donc, de la plupart des préceptes de la Cartilla del Emigrante, permettrait alors de dessiner le profil du migrant espagnol comme élément actif dans son devenir journalier et, par tant, comme expression individuelle et collective de l'hispanisme en Amérique.

Mots-clés: migration, Espagnols, législation, hispanisme. 


\section{Introducción}

Los procesos independentistas de las cuatro posesiones españolas continentales en América dieron lugar a un cambio en la condición de los peninsulares en las nuevas repúblicas, ya que de súbditos pasaron a ser extranjeros. El desconocimiento por parte de la Corona de la condición soberana de los estados independizados y, por ende, la inexistencia de nexos diplomáticos en las décadas de 1820 y 1830, así como las limitantes legales en materia migratoria a esos lugares, en ningún momento fueron un obstáculo para la movilidad de españoles en ambos lados del Atlántico. Por el contrario, los vínculos personales y la amplia gama que de ellos se desprendieron, los programas de colonización de varias naciones en América Latina, etc., le dieron forma a una cultura migratoria que, de una u otra manera, fue parte de la dinámica en la que participaron los españoles previa a la apertura normativa de 1853 .

Respecto a la emigración de españoles a América diversos argumentos se expusieron por parte de legisladores, políticos y hombres de letras, como lo ha puntualizado Blanca Sánchez Alonso; ejercicio que fue tardío y distó de abordar la cuestión con mayores elementos desde lineamientos políticos, sociales y económicos, como se hacía en otros países del entorno europeo, tales como Inglaterra e Italia a lo largo de buena parte del siglo XIX ${ }^{2}$. En este entorno y bajo un escenario de singular importancia como fue el centenario de la independencia de las repúblicas latinoamericanas en 1910, se publicó la Cartilla del Emigrante con el auspicio de la Unión Ibero-Americana, lo que denota el interés y perspectiva de la Unión respecto a la emigración española a América; causa que se advierte debería sustentarse en una decisión guiada por el corpus normativo, cuyo trayecto en consecuencia se orientaría bajo criterios médico-sanitarios, asistenciales, entre otros, que redundarán en beneficio de quien emprendía el viaje, así

2 Blanca Sánchez Alonso, Los mitos de la emigración española (Madrid: Universidad CEU San Pablo, 2015), 11-35; Blanca Sánchez Alonso. Las causas de la emigración española 1880-1930 (Madrid: Alianza Editorial, 1995), 62-93. 
como a posesionar de mejor manera la imagen y el papel de los españoles establecidos en Ultramar.

El seguimiento que hemos realizado sobre el doctor Jesús María Rísquez Alfonso y el catedrático Melchor Ordóñez, autores de la Cartilla del Emigrante, hasta el momento no nos permite relacionarlos directamente con la Unión IberoAmericana, ni con el entorno institucional y personal de sus socios o, en su defecto, con las ramificaciones que se derivaban de sus intereses en el orden económico, político, diplomático y cultural, entre otros, en América Latina, que ha sido objeto de análisis de acusiosos especialistas. Bajo esta perspectiva, el trabajo de Rísquez y Ordóñez, lo insertamos dentro de los trabajos -y sus elementos discursivos- que se publicaron en España tanto en pro como en contra respecto a la salida de españoles a Ultramar y sus consecuencias, que se realizaron con la finalidad de ofrecer a los potenciales emigrantes elementos que les permitieran orientar de la mejor manera sus pretensiones de viaje.

Este trabajo se centra en uno de los momentos más importantes en la migración de españoles a varios países del continente americano, previo el inicio de la Primera Guerra Mundial y la crisis económica internacional de la década de los años veinte que trastocó la movilidad internacional. Por lo que nuestro objetivo es hacer el seguimiento de los planteamientos y propuestas presentes en la Cartilla del Emigrante, con el fin de determinar qué aspectos eran los que más preocupaban a los intelectuales hispanoamericanos con respecto a la movilidad transatlántica.

Detrás de la Cartilla del Emigrante, podemos advertir el posesionamiento que tenía la Unión Ibero-Americana en materia migratoria, es decir, que se apostaba por una movilidad internacional sujeta a los preceptos legales de ambos lados del Atlantico, los preparativos de la travesía y los costos de la misma, los cuidados y la atención médica que el potencial viajero debería observar antes del embarque, el conocimiento previo de las condiciones y recursos de los países de destino, etc. En fin, propuestas pertinentes que la experiencia del 
transvase de los españoles desde distintos frentes: personal, regional, colectivo, institucional, entre otras, había salvado en más de alguna cuestión.

Por lo tanto, respecto a la Unión Ibero-Americana debemos decir que de ninguna manera es objeto de este trabajo, por lo que solamente ubicamos su papel como promotor de la Cartilla y su utilidad para los emigrantes españoles. Respecto a su difusión e impacto entre los potenciales migrantes solamente contamos con referencias de otros académicos que han abordado la movilidad transatlántica. No desconocemos la importancia de la Unión como referente del hispanismo en América Latina, sobre lo que hay una literatura especializada, en particular desde una perspectiva cultural. Tampoco pretendimos adentrarnos en la línea de los trabajos sobre la política exterior y las relaciones de España con los países de América Latina, que en sí es una línea de estudio y en la que la Unión tenía singulares intereses.

\section{Algunas consideraciones sobre la emigración española}

A partir de la segunda mitad de la década de 1830, la emigración española a América se perfiló como un importante fenómeno poblacional en ascenso que se presentó en distintas localidades y regiones de la Península, como lo evidencian los estudios correspondientes a la etapa pre estadística, que la han cuantificado parcialmente conforme con los cauces legales y clandestinos utilizados por los migrantes ${ }^{3}$. La participación del gobierno de Madrid en el control de las salidas a través de un progresivo marco normativo en la materia, así como el reconocimiento de naciones libres y el establecimiento de relaciones diplomáticas con sus otrora posesiones coloniales, la puesta en marcha de varias instancias oficiales e instrumentos para llevar cuenta de quienes abandonaban el país y sus tentativos lugares de destino, paulatinamente se precisaron

3 José Manuel Pérez Prendes y Muñoz de Arraco, El marco legal de la emigración española en el Constitucionalismo (Gijón: Fundación Archivo de Indianos, 1993); Sánchez Alonso, Las causas de la emigración..., 105-110. 
a lo largo del siglo XIX y primeras décadas de la siguiente centuria ${ }^{4}$.

En la década de 1860 la emigración española a América Latina distaba de tener carácter masivo, ya que en el mejor de los casos las experiencias legislativas compartidas entre ambas orillas del Atlántico favorecieron la migración colectiva a ciertos países, como se registró en Argentina y Brasil, mientras que en otros predominó su perfil individual, como en Chile, Venezuela y México, por mencionar algunos ${ }^{5}$. Además sobre el particular habría que tener en cuenta otros factores que favorecieron el arribo como la estabilidad social, política y el desarrollo económico que experimentaron algunos de los lugares de acogida. Los resultados alcanzados por la emigración peninsular hasta ese momento fueron la antesala de lo que Nicolás Sánchez Albornoz puntualizó como «la emigración en masa», que corresponde al periodo que transcurrió entre 1880

4 César Yáñez Gallardo. La emigración española a América (siglos XIX y XX). (Gijón: Principado de Asturias, Archivo de Indianos, Caja de Asturias, 1994); Ricardo Evaristo Santos. Política migratoria española a Iberoamérica: aporte Brasil 1890-1950. (La Coruña: Edicios do Castro, 1996); Compilación de las disposiciones emitidas sobre emigración. (Madrid: Inspección General de emigración, Imprenta Sáenz Hermanos, 1933). Entre las disposiciones legislativas emitidas por el gobierno español habría que mencionar la Real Orden Circular de 16 de septiembre de 1853, que proscribió las limitantes que existían para que los españoles emigraran a las colonias insulares y americanas, así como a varios países de Iberoamérica, la Ley de emigración de 1907 que reconoció la libertad de emigrar. Mientras que entre las instituciones encargadas del ramo destacaron la creación de la Sección de Emigración dentro de la Dirección General de Agricultura en mayo de 1882, el Instituto Geográfico Estadístico en 1891, el Consejo Superior de Emigración e Instituto Español de Emigración que inició sus trabajos en 1907. Respecto a los instrumentos cuantitativos figuraron los Anuarios Estadísticos de 1860-1861, el Registro de la Dirección de Aduanas, las estadísticas del Consejo Superior de Emigración.

5 Diversas acciones gubernamentales y particulares se implementaron para atraer extranjeros a varios países de América Latina a lo largo del siglo XIX, como fue el fomento a la colonización y establecimiento de colonias agrícolas avaladas por leyes y decretos en la materia, cuyas labores se realizaron a través de agencias y compañías que se establecieron en varias naciones europeas. $\mathrm{Al}$ respecto los mejores resultados se observaron en Argentina y Brasil principalmente, ya que contaron con recursos económicos para la empresa, así como la exención de impuestos de importación, sobre todo de efectos destinados a la agricultura, pago de pasajes, hospedaje provisional, concesiones de tierras, etc. Otras medidas que se implementaron para atraer migrantes estuvieron relacionadas con el disfrute de los derechos ciudadanos constitucionales (acceso a la propiedad, libertad de cultos, naturalización, etc.), con la salvedad de los de índole política, leyes de inmigración y de extranjería. Elda González, «La llegada», en Historia general de la emigración española a Iberoamérica, coord. Pedro A. Vives, Pepa Vega y Jesús Oyamburu (Madrid: CEDESAL, 1992), 259-274. 
y 1930; transvase en el que destacaron gallegos, asturianos, vascos, catalanes y canarios, principalmente ${ }^{6}$.

Entre los factores que determinaron la salida «en masa» de españoles, es conveniente tener presentes varias cuestiones que impactaron en el contexto internacional, como el progresivo proceso de industrialización que se observó en varios países de Europa continental, el desempleo, la movilidad poblacional del campo a la ciudad, la articulación y especialización del mercado mundial, la exportación de capitales, la revolución tecnológica en los transportes, etc. ${ }^{7}$ Mientras que en España además interactuaron como agentes expulsores el fracaso de la modernización agrícola, que distó de rebasar los niveles de subsistencia, el incremento de la población, el lento desarrollo industrial y su impacto económico y social, tanto en el entorno nacional como regional. ${ }^{8}$

De esta manera, la progresiva movilidad transatlántica se manifestó en la Península en distintos escenarios, ya que las ausencias se dejaron sentir en el incumplimiento del servicio militar, el incremento de la migración clandestina y más tarde legal tanto colectiva como individual, el despoblamiento, etc. Ante este panorama, el Gobierno de la Restauración se vio obligado a plantear la cuestión como un asunto de Estado, ya que en función de sus particularidades demandaba ser

$6 \quad$ Nicolás Sánchez Albornoz, comp. Españoles hacia América. La emigración en masa, 1880-1930. (Madrid: Alianza Editorial, 1995), 9-29. Véase también Blanca Sánchez Alonso. «La emigración española a la Argentina, 1880-1930», en Españoles hacia América. La emigración en masa, 1880-1930, comp. Nicolás Sánchez Albornoz (Madrid: Alianza Editorial, 1995), 205-234; José de Souza Martins. «La inmigración española en Brasil y la formación de la fuerza de trabajo en la economía cafetalera, 1880-1930», en Españoles hacia América..., 249-269, Herbert Klein, La inmigración española en Brasil (Gijón: Archivo de Indianos, Ministerio de asuntos Sociales, Dirección General de Migraciones, 1996), José C. Moya. Cousins and strangers. Spanish inmigrants in Buenos Aires, 1850-1930. (Los Angeles: University of California Press, 1998).

$7 \quad$ Klaus J. Bade. Europa en movimiento. Las migraciones desde fines del siglo XVIII hasta nuestros días. (Barcelona: Crítica, 2003); Máximo Livi Bacci. Historia de la población europea. (Barcelona, Crítica, 1999).

8 Ángel Bahamonde. "Los dos lados de la migración transoceánica», en Historia general de la emigración española a Iberoamérica, coord. Pedro A. Vives, Pepa Vega y Jesús Oyamburu (Madrid: CEDESAL, 1992), 93-132; Sánchez Alonso. Las causas de la emigración española... 
atendido a través de una investigación que permitiera determinar las causas que originaban la emigración; empresa que llevó a cabo en 1881 la Comisión Especial que buscaría los medios para contenerla ${ }^{9}$.

En virtud de los mínimos resultados obtenidos por las autoridades en su afán de controlar el flujo migratorio transatlántico, que indistintamente se acogía tanto a los preceptos legales como a los proscritos al momento de viajar con destino a algún país de América Latina ${ }^{10}$, el 7 de octubre de 1902 el Ministerio de Gobernación informó a los gobernadores de las provincias, la derogación de la Real Orden de 10 de noviembre de $1883 \mathrm{y}$, por ende, el establecimiento de nuevos lineamientos, cuyo objetivo era simplificar los procedimientos de salida, entre los que figuraron la desaparición del permiso de embarque que era expedido por dichas instancias.

También se estableció que los pasajeros, tanto hombres mayores de cuarenta años como mujeres de veintitrés y emancipadas, podrían viajar sin otro requisito que su cédula personal. En relación con los varones mayores de quince años, estos tendrían la obligación de comprobar que habían cumplido con el servicio militar o, en su defecto, encontrarse exentos de dicha responsabilidad, entre otras cuestiones; en este sentido habría que recordar que este sector de la población era el que presentaba un alto índice de incidencia al margen de la ley y el cumplimiento de los derechos civiles-cívicos ${ }^{11}$.

$9 \quad$ Sánchez Alonso. Las causas de la emigración española..., 70. De acuerdo con la autora, en el ánimo de las autoridades de la Restauración también influyó la muerte de varios españoles en Argelia en el año de 1881. Las conclusiones alcanzadas por la Comisión distaron de puntualizar las causas del problema en sí, lo que vino a reforzar los lineamientos poblacionistas que se manifestaban en contra de la migración y sus efectos negativos para España.

10 Las opciones operativas por las que se decantaron las autoridades españolas a finales de la década de 1880, fueron brindar protección oficial a los potenciales migrantes ante la labor de agentes y enganchadores foráneos -sobre todo a evitar las salidas clandestinas-, encausar la movilidad poblacional hacia las colonias e incentivar la colonización interior. Sánchez Alonso. Las causas de la emigración española..., 73-82.

11 Compilación de las disposiciones dictadas sobre emigración. Real Orden del Ministerio de Gobernación señalando las formalidades que han de observarse para autorizar los embarques de los emigrantes a ultramar, 7 de octubre de 1902, LIILV. En esencia, la Real Orden del Ministerio de Gobernación de 10 de noviembre de 
Más tarde, el 21 de diciembre de 1907, se publicó la Ley de Emigración que reconoció la libertad de todo español para emigrar a América, Asia u Oceanía, acogiéndose a los beneficios que le concedía un pasaje retribuido o gratuito. Las limitantes en la materia únicamente restringieron la salida de los individuos que estaban sujetos a servicio militar, o bien, a proceso judicial pendiente. Por su parte, el Consejo de Ministros se abrogó la facultad de reducir la salida de menores de edad. También la Ley contempló condicionantes en lo tocante al viaje de mujeres casadas, menores de edad, solteras menores de veintitrés años, sobre todo si no contaban con la autorización de esposos, padres o tutores. Respecto a todas aquellas cuestiones relacionadas con la migración colectiva, cuya finalidad era la colonización, estas dependerían de la autorización del Consejo de Ministros, previo informe del Consejo Superior de Migración ${ }^{12}$.

La magnitud que alcanzó la movilización migratoria española en América Latina, en buena medida incentivada tanto por factores internos como externos, se puede constatar en las cifras de la estadística anual de salidas que se registraron en España entre 1885 y 1904, cuyos principales destinos eran Argentina, Brasil, Cuba y en menor escala varios países del continente, que en conjunto sumaron 977,542 individuos ${ }^{13}$. César Yánez Gallardo puntualizó que a la par con la migración a Cuba, que se vio reducida a raíz de la Guerra de Independencia (1895-1898), se perfilaron nuevos flujos que condujeron a los peninsulares a América del Sur, en particular a Argentina, Brasil y Uruguay. Respecto al periodo 1905-1914, se puede decir que esta etapa fue dominada nuevamente por la emigración a Argentina, a la vez que habría que señalar la importancia que tuvieron las salidas a Brasil y Cuba, como se puede apreciar en el cuadro 1, que destaca de igual manera

1883, que se ocupaba de los pormenores del embarque de los viajeros con destino a Iberoamérica no reportó mayores diferencias respecto a los lineamientos sancionados en su similar de 16 de septiembre de 1853, con la salvedad de la autorización que debería emitir el gobernador de la provincia donde debería de zarpar el barco.

12 Compilación de las disposiciones dictadas sobre emigración, 5-17. Ley de emigración de 21 de diciembre de 1907.

13 César Yáñez Gallardo, La emigración española a América, 115. 
el lapso 1907-1914 como el de mayor migración de españoles hacia América, que fue del orden de 1,344.147 individuos, en su mayoría hombres jóvenes ${ }^{14}$.

\begin{tabular}{|c|c|c|c|c|c|}
\hline Año & Argentina & Brasil & Cuba & $\begin{array}{c}\text { Otros } \\
\text { países de } \\
\text { América }\end{array}$ & $\begin{array}{c}\text { Total } \\
\text { españoles } \\
\text { en América }\end{array}$ \\
\hline 1905 & 53.122 & 19.217 & 34.957 & 5.096 & 112.392 \\
\hline 1906 & 79.517 & 23.298 & 20.551 & 7.574 & 130.940 \\
\hline 1907 & 82.606 & 7.603 & 21.857 & 14.549 & 126.615 \\
\hline 1908 & 125.497 & 13.677 & 18.959 & 10.761 & 168.894 \\
\hline 1909 & 86.798 & 15.069 & 22.848 & 9.650 & 134.365 \\
\hline 1910 & 131.466 & 20.834 & 27.714 & 10.872 & 190.886 \\
\hline 1911 & 118.723 & 23.335 & 30.560 & 9.544 & 182.162 \\
\hline 1912 & 165.662 & 32.150 & 33.391 & 9.229 & 240.432 \\
\hline 1913 & 122.271 & 36.037 & 35.755 & 11.267 & 205.330 \\
\hline 1914 & 52.186 & 12.424 & 22.836 & 8.017 & 95.463 \\
\hline Total & $1,017.848$ & 203.644 & 269.428 & 96.559 & $1,587.479$ \\
\hline
\end{tabular}

Cuadro 1. Emigración española a América, 1905-1914.

Fuente: elaboración propia con base en Yánez Gallardo, 1994, p. 115.

\section{La Unión Ibero-Americana y la Cartilla del Emigrante}

A la interacción de los factores internos y externos arriba mencionados que intervenían tanto en pro como en contra en el transvase transatlántico español, podemos agregar otros de diversa índole que pretendían de alguna forma convertirse en un referente que tendía a reiterar y reforzar la presencia e influencia cultural de España en el continente americano. En este sentido podemos citar la labor de la Unión IberoAmericana, sociedad fundada en Madrid en enero de 1885 como

14 César Yáñez Gallardo, La emigración española a América..., 113-124. El máximo histórico de acuerdo con el autor fue de 240.432 salidas anuales en 1912. La empresa migratoria en un primer momento se podría decir, de acuerdo con las cifras, que era masculina; sin embargo, la presencia de las mujeres se hizo constante en virtud a su papel dentro de la movilidad familiar o bien, en su defecto, cuando se trató de reunificación familiar, sin descartar su incorporación al trabajo dentro y fuera del hogar en varios países de acogida. 
asociación internacional, científica-literaria y económica ${ }^{15}$. El propósito de la Unión era:

[...] estrechar las relaciones sociales, económicas, científicas, literarias y artísticas de España, Portugal y las naciones americanas... y preparar la más estrecha unión comercial en el porvenir... (lo que permitirá que se) aumenten las relaciones de todo género suavizando asperezas é infundiendo amor y confianza para acercarse más y más cada dia por medio de la literatura, la ciencia, la industria y el arte al noble propósito que se persigue» ${ }^{16}$.

En la Unión Ibero-Americana participaron en calidad de socios connotados hombres de Estado tanto liberales como conservadores de la Restauración (1874-1923), como Segismundo Moret, Antonio Cánovas del Castillo, Práxedes Mateo Sagasta, Francisco Silvela, entre otros. De igual manera figuraron varios integrantes de la nobleza -Grandes de España-, como el Marqués de Cerralbo, el Marqués de Comillas, el Duque de Veragua, el Conde las Navas, por mencionar algunos que ocuparon distintos ministerios de gobierno, y destacaron como empresarios, filántropos, profesionistas, etc. Hicieron parte de la nómina de socios presidentes, exmandatarios y funcionarios de primer nivel de varios países de América Latina, como Rafael Zaldivar (presidente de El Salvador), el general Joaquín Crespo (presidente de Venezuela), Gregorio Pacheco (presidente de Bolivia), Domingo Santa María (presidente de Chile), Ignacio

15 Unión Ibero-Americana, Estatutos y reglamento aprobados en Junta General el 25 de enero de 1885 y el 5 de febrero por la autoridad competente. (Madrid: Imprenta de Moreno y Rojas, 1885), 5, 7-8. Estatutos, Arts. 1, fracción 1 y 12. Véase también Unión Ibero Americana. Estatutos y reglamento reformados en Junta General extraordinaria de los días 15 y 16 de enero de 1886, y aprobados por la autoridad competente el 28 del mismo mes y año. Memoria anual, estado económico, Consejo de Gobierno y Junta Directiva, lista de socios protectores, de mérito y de número, de adheridos. (Madrid: Imprenta de Alfonso Rodero, 1886).

16 Unión Ibero-Americana, Estatutos y reglamento, 5. Estatutos, Art. 2, fracciones 1-3, 6, 8-10. Con la finalidad de alcanzar tales objetivos se planteó que las naciones interesadas celebraran tratados literarios que garantizaran los derechos de autores y editores, así como la impresión y venta a precios módicos de las obras de mayor reconocimiento, facilitar el canje de periódicos entre España, Portugal y las naciones americanas. Así mismo se consideró la formación de Círculos Ibero Americanos en todos los pueblos de España, Portugal y en los países de Iberoamérica. También se consideró de suma importancia la habilitación de los títulos facultativos expedidos por las instituciones educativas para el ejercicio regular de las profesiones. 
L. Vallarta (Secretario de Relaciones Exteriores de México), por citar algunos ${ }^{17}$. En breve, varias repúblicas del continente se hicieron eco de la propuesta de la Unión, lo que de una forma u otra permitía la comunicación con la sede en Madrid y la consecución de intereses afines ${ }^{18}$.

Entre las actividades que la Unión realizó sobresalió su participación en la conmemoración del Cuarto Centenario del Descubrimiento de América en octubre de 1892. Al respecto cabe destacar el proyecto que presentó a la reina regente María Cristina alusivo a esta efeméride; iniciativa que se complementó con la propuesta de Cánovas de Castillo, presidente del Consejo de Ministros, quien a su vez era socio de la Unión, para que se declarara tal fecha como fiesta perpetua. A pesar de los esfuerzos, solo se logró que se considerara por única vez como festivo el 12 de octubre por medio de Real Decreto, en tanto en lo sucesivo fue olvidada esta fecha por espacio de veinte años. Fuera de España la iniciativa de la Unión fue secundada en varios países de América Latina, como sucedió en México ${ }^{19}$.

Con mejores resultados la Unión Ibero-Americana se alzó en el año de 1900 con su propuesta de estrechar las relaciones con los países de América Latina, gracias a que formó parte de las instancias que convocaron en Madrid el Congreso Social y Económico Hispano-Americano. Como puntualiza Isabel García-Montón,

17 Unión Ibero-Americana. Estatutos y reglamento. En la relación de integrantes de la Unión se encontraron representantes en La Habana, Puerto Rico, Filipinas, Colombia, Panamá, Perú, Guatemala, Costa Rica y Argentina.

18 Sobre la influencia y presencia de la Unión Ibero Americana en México véase Alfredo Rajo Serventich. "Las dimensiones del hispanismo e hispanoamericanismo», Latinoamérica, $\mathrm{n}^{\circ} 47$ (2008): 97. El autor menciona el establecimiento de otros centros en Venezuela, Brasil, Perú, Guatemala, Nicaragua, El Salvador, República Dominicana, Colombia, Costa Rica, Honduras, Chile y más tarde en Argentina. Carlos M. Rama, Historia de las relaciones culturales entre España y la América Latina. Siglo XIX. (México: Fondo de Cultura Económica, 1982), 180-198.

19 Miguel Rodríguez, Celebración de "la raza». Una historia comparativa del 12 de octubre. (México: Universidad Iberoamericana, 2004), 27-30. El Congreso se inauguró el 10 de noviembre de 1900. Las sesiones giraron en torno a 11 mesas de trabajo. 
[...] la preocupación central del Congreso fue la reorganización del comercio y las relaciones económicas transatlánticas, el contexto en que se produjeron los debates favoreció que se hiciese una reflexión compartida sobre la conveniencia de articular un sistema interestatal que agrupara a las naciones del ámbito iberoamericano ${ }^{20}$.

Entre los logros a los que se llegó en el Congreso cabría mencionar: la celebración de una asamblea pedagógica hispanoamericana que arbitrara las bases comunes para una enseñanza unificada, la celebración de congresos científicos en todas las materias relevantes, la convalidación de títulos académicos y profesionales, etc. También de singular importancia fue la mediación de la Corona española en cuestiones de límites y arbitraje ente Perú y Ecuador en $1905^{21}$.

Después de la celebración del Congreso Hispanoamericano, la Unión Ibero-Americana participó en los fastuos del primer centenario de la independencia de las naciones latinoamericanas. Con este propósito y la intención de brindarles a los españoles que aspiraban a incorporarse a la empresa migratoria los elementos informativos necesarios, se lanzó en 1910 la convocatoria para la elaboración de una cartilla que fuera útil al potencial emigrante. Sobre esta cuestión habría que puntualizar que la Unión era partidaria de transvase, ya que «favorecía el españolismo y la intimidad hispanoamericana». Por lo tanto sus recomendaciones giraban en torno a educar, enseñar, cuidar y dirigir a los futuros emigrantes ${ }^{22}$. El doctor Jesús María Rísquez Alfonso y el catedrático Melchor Ordóñez fueron los ganadores del certamen, con el trabajo titulado Cartilla del Emigrante. En palabras de la Unión Ibero-Americana, la Cartilla de Rísquez Alfonso y Ordóñez tenía la virtud de «presentar recopiladas en forma breve y sencilla las noticias cuyo conocimiento es

20 Isabel García-Montón G.-Baquero, «El Congreso Social y Económico Hispanoamericano de 1900: un instrumento del hispanoamericanismo modernizador», Revista Complutense de Historia de América, $\mathrm{n}^{\circ} 25$ (1999): 281.

21 García-Montón G.-Baquero. «El Congreso Social y Económico...», 292-293.

22 C. Martín Montalvo, Ma. Rosa Martín de la Vega y Ma. Teresa Sobrado Solano. «El hispanoamericanismo, 1880-1930», Quinto Centenario 8, (1985): 155. 
más indispensable a todo aquél que se disponga a emigrar». ${ }^{23}$ De acuerdo con Isidro Sepúlveda, el objetivo que se pretendió con el concurso y publicación de la Cartilla del Emigrante, se alcanzó con creces ya que se difundió y fue del conocimiento público en y fuera de España ${ }^{24}$.

En las primeras páginas de la Cartilla se advierte la concepción y justificación de la emigración por parte de Rísquez y Ordóñez, así como la que suscribía y avalaba la Unión Ibero-Americana, ya que la consideran como «una condición inherente á las necesidades humanas, y de ninguna manera un desconocimiento de los deberes de la nacionalidad, así como el estancamiento de las poblaciones es un signo de pobreza y decadencia ${ }^{25}$. De esta manera los autores dejaron en claro que la movilidad de la población era una condicionante de su bienestar, en el cual no deberían quedar al margen sus derechos y obligaciones civiles, es decir, que no justificaban las salidas clandestinas del país. También en este sentido habría que considerar que de forma velada dejaron ver la pobreza en que se encontraba parte de la población española, lo que actuaba como un elemento que los impulsaba hacia el exterior. Es de llamar la atención que en ningún momento se

23 Jesús María Rísquez Alfonso y Melchor Ordóñez, Cartilla del Emigrante 1910, (Madrid: Imprenta de los Hijos de M. G. Hernández, 1910). Advertencia preliminar, 6. Respecto a los ganadores del certamen, se tienen pocas referencias. Al efecto podemos decir que Melchor Ordóñez era originario de Cebú, Filipinas. Ordóñez realizó sus estudios en Madrid y Salamanca. Fue abogado y catedrático en la Escuela Superior de Comercio de Canarias y en el Instituto General y Técnico de La Laguna. Viajó por América y se desempeñó como funcionario del Consejo Supremo de Emigración. Mientras que de Jesús María Rísquez se mencionó que era médico de origen venezolano que había estudiado en España y que ejercía su carrera en Málaga. $A B C$, Madrid, 11 de febrero de 1910, p. 11; «El Colegio. Presidente. Melchor Ordóñez Alonso", Ilustre Colegio Oficial de Titulados Mercantiles y Empresariales de Santa Cruz de Tenerife, acceso el 28 de septiembre de 2013, http://www.cotime.es/el-colegio/ presidentes/249-melchorordoñez-alonso.htm.

24 Isidro Sepúlveda, El sueño de la Madre Patria. Hispanismo y nacionalismo, (Madrid: Fundación Carolina/Centro de Estudios Hispánicos e Iberoamericanos/ Marcial Pons, 2005), 369.

25 Rísquez Alfonso y Ordóñez, Cartilla del Emigrante..., 10. La Cartilla estaba compuesta de una advertencia preliminar, diez capítulos y un resumen. En términos generales el contenido de dicha publicación comprendía consideraciones sobre la emigración de los españoles en América, los documentos necesarios para realizar la travesía, líneas de navegación y costo del viaje, los migrantes en los lugares de destino y las autoridades a los que podían acudir en caso necesario, entre otros aspectos. 
alude a la tradición de los peninsulares por la migración hacia América y las redes familiares y de paisanaje que se habían establecido a lo largo del siglo XIX, entre otras cuestiones.

En este sentido resulta pertinente apuntar lo que los autores señalaron sobre la decisión de emigrar: «Emigra aquel que no encuentra en su propio país manera de desarrollar sus aptitudes, y busca un lugar más ajustado á ellas el modo de satisfacer sus ansias de trabajo y producción $»^{26}$. Dada la importancia de este fenómeno poblacional puntualizaron que: «la emigración es uno de los beneficios resultantes del trato entre los pueblos, y toca á los gobiernos reglamentarla, para evitar los inconvenientes que pueden resultar del mal empleo del derecho de migrar» ${ }^{27}$. Al respecto baste decir que en la Cartilla se dio espacio al marco normativo tanto español como al de los países de destino de los migrantes; cuyo conocimiento previo de quienes emprendían el viaje debería de guiar su proceder y evitar problemas en el punto de partida y destino.

Entre los factores que a juicio de los autores de la Cartilla destacaban para incentivar la migración a América señalaron que:

[...] Durante cuatro siglos fueron posesiones españolas, y siguen siendo las hijas cariñosas de la madre España, y si se atiende, finalmente á que el idioma es el mismo y la religión y las costumbres son también las mismas, se encontrara necesariamente indicado que el camino más ventajoso para los españoles que deseen ó necesiten emigrar es el de la América hispana $[\ldots]^{28}$.

Tanto Rísquez como Ordóñez puntualizaron la importancia que tenía para los emigrantes peninsulares la dedicación al trabajo, ya que era un elemento importante de cara a la integración económica en las sociedades receptoras

\footnotetext{
26 Rísquez Alfonso y Ordóñez, Cartilla del Emigrante..., 11.

27 Rísquez Alfonso y Ordóñez, Cartilla del Emigrante..., 12. Sobre esta cuestión los autores en el capítulo IX dieron a los potenciales migrantes las generalidades del marco migratorio español, así como el de Argentina, Bolivia, Brasil, Costa Rica, Cuba, Chile, Guatemala, Perú, México, Uruguay y Venezuela.
}

28 Rísquez Alfonso y Ordóñez, Cartilla del Emigrante..., 13. 
de varias naciones del continente americano, como bien lo expresaron en los siguientes términos:

[...] el trabajo y la prosperidad de los españoles de Ultramar ejerce una influencia notable en el desarrollo económico de las provincias peninsulares; que el establecimiento y arraigo de los emigrantes españoles en la libre y próspera América, representa mucho para la resurrección del carácter y la vida normal de la raza ibérica $[\ldots]^{29}$.

Por lo que refería a la información relativa a los puertos españoles habilitados para la salida de emigrantes, los autores de la Cartilla señalaron los siguientes: Alicante, Almería, Barcelona, Bilbao, Cádiz, Coruña, Las Palmas (Gran Canaria), Málaga, Palma de Mallorca, Santa Cruz de Tenerife, Santa Cruz de la Palma, Santander, Valencia, Vigo y Villagarcía. Es decir, puertos en todos los litorales de la Península, así como en sus posesiones insulares inmediatas ${ }^{30}$. Para la realización del viaje transatlántico, Rísquez y Ordóñez sugerían los servicios de las siguientes compañías, como se especifica en el cuadro 2:

\begin{tabular}{|c|c|c|c|}
\hline Compañía & Sede & Representante en España & $\begin{array}{c}\text { Número } \\
\text { de barcos }\end{array}$ \\
\hline Chargeurs Reunis & $\begin{array}{c}\text { París, } \\
\text { Francia }\end{array}$ & $\begin{array}{c}\text { Antonio Conde e Hijos en } \\
\text { Vigo }\end{array}$ & 22 \\
\hline Loyd Sabaudo & Turín, Italia & $\begin{array}{c}\text { Domingo Casanovas } \\
\text { Clement en Tarragona }\end{array}$ & 5 \\
\hline $\begin{array}{c}\text { Giusepe Zino fu } \\
\text { Domenico }\end{array}$ & $\begin{array}{c}\text { Savona, } \\
\text { Italia }\end{array}$ & Rómulo Bosch y Alcina & 2 \\
\hline $\begin{array}{c}\text { Hamburg } \\
\text { Americanische } \\
\text { packetfahart Actien } \\
\text { Gesellchaft }\end{array}$ & $\begin{array}{c}\text { Hamburgo, } \\
\text { Alemania }\end{array}$ & $\begin{array}{c}\text { Ramón Satorre de } \\
\text { Barcelona }\end{array}$ & 44 \\
\hline \multicolumn{3}{|c}{} & \multicolumn{2}{|c}{} \\
\hline
\end{tabular}

29 Rísquez Alfonso y Ordóñez, Cartilla del Emigrante..., 14. La apreciación que en su momento realizaron los autores de la Cartilla y que hemos citado arriba, ha sido retomada y analizada recientemente por especialistas de ambas orillas del Atlántico desde una óptica económica comparada. Sobre el particular véase Rafael Dobado, Aurora Gómez Galvarriato y Graciela Márquez, México y España. ¿ Historias económicas paralelas? (México: Fondo de Cultura Económica, 2007).

30 Rísquez Alfonso y Ordóñez, Cartilla del Emigrante..., 19, 25-26. 


\begin{tabular}{|c|c|c|c|}
\hline Compañía & Sede & Representante en España & \begin{tabular}{|l|} 
Número \\
de barcos
\end{tabular} \\
\hline $\begin{array}{c}\text { Hamburg } \\
\text { Sudamericanische } \\
\text { Dampfschiffahrts } \\
\text { Gessellschatt }\end{array}$ & $\begin{array}{l}\text { Hamburgo, } \\
\text { Alemania }\end{array}$ & $\begin{array}{c}\text { Francisco Setuaín de } \\
\text { Madrid }\end{array}$ & 35 \\
\hline $\begin{array}{l}\text { Norddeutscher } \\
\text { Lloyd }\end{array}$ & $\begin{array}{l}\text { Bremen, } \\
\text { Alemania }\end{array}$ & $\begin{array}{c}\text { Francisco Setuaín de } \\
\text { Madrid }\end{array}$ & 69 \\
\hline Nelson Line & $\begin{array}{l}\text { Liverpool, } \\
\text { Gran } \\
\text { Bretaña }\end{array}$ & $\begin{array}{l}\text { Francisco Setuaín de } \\
\text { Madrid }\end{array}$ & 6 \\
\hline $\begin{array}{c}\text { Generale } \\
\text { Transatlantique }\end{array}$ & $\begin{array}{c}\text { París, } \\
\text { Francia } \\
\end{array}$ & $\begin{array}{c}\text { Francisco Setuaín de } \\
\text { Madrid }\end{array}$ & 20 \\
\hline $\begin{array}{l}\text { Transatlántica } \\
\text { Española }\end{array}$ & Barcelona & Javier Gil Becerril & 22 \\
\hline $\begin{array}{c}\text { Societé Genérale } \\
\text { de Transports } \\
\text { Maritimes á } \\
\text { Vapeur }\end{array}$ & $\begin{array}{l}\text { París, } \\
\text { Francia }\end{array}$ & Fermín de Izaguirre & 9 \\
\hline $\begin{array}{c}\text { Sociedad Anónima } \\
\text { de Navegación } \\
\text { Trasatlántica } \\
\end{array}$ & Barcelona & Joaquín de Arumí & 7 \\
\hline $\begin{array}{l}\text { Royal Mail Steam } \\
\text { Packet Co. }\end{array}$ & $\begin{array}{l}\text { Londres, } \\
\text { Gran } \\
\text { Bretaña }\end{array}$ & Estanislao Durán & 20 \\
\hline Pinillos Izquierdo & Cádiz & & 8 \\
\hline $\begin{array}{l}\text { Pacific Stema } \\
\text { Navegation Co. }\end{array}$ & $\begin{array}{l}\text { Liverpool, } \\
\text { Gran } \\
\text { Bretaña }\end{array}$ & Sobrinos de J. Pastor & 18 \\
\hline $\begin{array}{c}\text { Koninlijke } \\
\text { Hollandsche Lloyd }\end{array}$ & $\begin{array}{l}\text { Amsterdam, } \\
\text { Holanda }\end{array}$ & Raimundo Molina & 5 \\
\hline $\begin{array}{c}\text { Boot Stmesageries } \\
\text { Maritimeseam Ship } \\
\text { Co. Limited } \\
\end{array}$ & $\begin{array}{l}\text { Liverpool, } \\
\text { Gran } \\
\text { Bretañal } \\
\end{array}$ & $\begin{array}{l}\text { Hijos de J. Barreras } \\
\text { (Vigo) }\end{array}$ & 8 \\
\hline $\begin{array}{l}\text { Manuel María de } \\
\text { Arrotegui }\end{array}$ & $\begin{array}{l}\text { Bermeo } \\
\text { (Vizcaya) }\end{array}$ & & 3 \\
\hline $\begin{array}{c}\text { Navigazione } \\
\text { Generale Italiana }\end{array}$ & Roma, Italia & $\begin{array}{c}\text { Ignacio Villavecchita } \\
\text { (Barcelona) }\end{array}$ & 16 \\
\hline La Veloce & $\begin{array}{l}\text { Génova, } \\
\text { Italia }\end{array}$ & $\begin{array}{c}\text { Ignacio Villavecchita } \\
\text { (Barcelona) }\end{array}$ & 11 \\
\hline Lloyd Italiana & $\begin{array}{l}\text { Génova, } \\
\text { Italia }\end{array}$ & Luis G. Pares & 7 \\
\hline
\end{tabular}




\begin{tabular}{|c|c|c|c|}
\hline Compañía & Sede & Representante en España & $\begin{array}{c}\text { Número } \\
\text { de barcos }\end{array}$ \\
\hline $\begin{array}{c}\text { Mesageries } \\
\text { Maritimes }\end{array}$ & $\begin{array}{c}\text { París, } \\
\text { Francia }\end{array}$ & Francisco Tapias & 3 \\
\hline $\begin{array}{c}\text { Liverpool Brazil } \\
\text { River Plate Co. }\end{array}$ & $\begin{array}{c}\text { Liverpool, } \\
\text { Gran } \\
\text { Bretaña }\end{array}$ & $\begin{array}{c}\text { Hijos de J. Barreras } \\
\text { (Vigo) }\end{array}$ & 10 \\
\hline Houlder Line Lted. & $\begin{array}{c}\text { Londres, } \\
\text { Gran } \\
\text { Bretaña }\end{array}$ & $\begin{array}{c}\text { Juan Tapias en } \\
\text { Liquidación (Vigo) }\end{array}$ & 5 \\
\hline $\begin{array}{c}\text { Argentine Cargo } \\
\text { Line Limited } \\
\text { Grandres } \\
\text { Bretaña }\end{array}$ & $\begin{array}{c}\text { Benigno Fernández y } \\
\text { Hno. (Vigo) }\end{array}$ & 4 \\
\hline $\begin{array}{c}\text { Atlantic and } \\
\text { Eastern Steamship } \\
\text { C. Litd. }\end{array}$ & $\begin{array}{c}\text { Liverpool, } \\
\text { Gran } \\
\text { Bretaña }\end{array}$ & $\begin{array}{c}\text { Manuel María de } \\
\text { Arrotegui (Bermeo, } \\
\text { Vizcaya) }\end{array}$ & 2 \\
\hline $\begin{array}{c}\text { Austro Americana } \\
\text { Fratelli Cosulick }\end{array}$ & $\begin{array}{c}\text { Trieste, } \\
\text { Italia }\end{array}$ & Manuel Bermejón & 2 \\
\hline $\begin{array}{c}\text { British and South } \\
\text { American Stema } \\
\text { Navigation }\end{array}$ & $\begin{array}{c}\text { Liverpool, } \\
\text { Gran } \\
\text { Bretaña }\end{array}$ & Francisco Setuain & 4 \\
\hline $\begin{array}{c}\text { Italia Societa di } \\
\text { Navegazione á } \\
\text { Vapore }\end{array}$ & $\begin{array}{c}\text { Génova, } \\
\text { Italia }\end{array}$ & Ignacio Villavecchia & 7 \\
\hline
\end{tabular}

Cuadro 2. Líneas marítimas recomendadas en la Cartilla del emigrante, 1910. Fuente: elaboración propia con base en Cartilla del Emigrante, pp. 19-25.

De acuerdo con los datos de la Cartilla, los puntos de partida donde se concentraron las actividades de las compañías navieras fueron Vigo, Coruña, Barcelona, Santander y Bilbao, ya que en ellos operaba el mayor número de compañías autorizadas por el Consejo Superior de Emigración que efectuaban la travesía transatlántica, como se señala en el cuadro 3. La información sobre las diversas empresas que realizaban el viaje entre ambas orillas del Atlántico, proporcionaba a los interesados suficientes elementos para elegir el mejor servicio ${ }^{31}$. Ante todo, se advertía la competencia

31 La ubicación de los puertos, como lo señala Alejandro Vázquez, vino a dar salida natural a los migrantes españoles inmediatos a su entorno regional, lo que de alguna manera permitía hacer algunas economías en los costos de traslado. De igual manera habría que tener en cuenta que los puertos en Lisboa, Oporto (Leixoes), Burdeos 
por el pasaje entre tanta opción, lo que muy probablemente hacía que las preferencias se decantaran por las de origen español, como la Transatlántica Española y la Sociedad Anónima de Navegación, Transatlántica de Barcelona que contaban con 29 buques, mientras que en Bermeo, Vizcaya, una de las mejores propuestas fue Manuel María Arrotegui, mientras que Pinillos Izquierdo hacía lo propio en la Coruña y Barcelona. Sin lugar a duda, que también fueron atractivas las ofertas que ofrecían las compañías británicas, alemanas, francesas e italianas.

\begin{tabular}{|c|c|c|c|c|}
\hline Vigo & Coruña & Barcelona & Santander & Bilbao \\
\hline $\begin{array}{c}\text { British and South } \\
\text { American Steam } \\
\text { Navegation }\end{array}$ & $\begin{array}{c}\text { Compañía } \\
\text { Transatlántica } \\
\text { Española }\end{array}$ & $\begin{array}{c}\text { Giusepe Zino fu } \\
\text { Domenico }\end{array}$ & $\begin{array}{c}\text { British and South } \\
\text { American Steam } \\
\text { Navegation }\end{array}$ & $\begin{array}{l}\text { Royal Mail Steam } \\
\text { Packet Co. }\end{array}$ \\
\hline $\begin{array}{l}\text { Argentine Cargo } \\
\text { Line Ltd }\end{array}$ & Pinillos Izquierdo & $\begin{array}{l}\text { Pinillos } \\
\text { Izquierdo }\end{array}$ & $\begin{array}{c}\text { Generale } \\
\text { Transatlatique }\end{array}$ & $\begin{array}{c}\text { Hamburg- } \\
\text { Americanische } \\
\text { Packetfahrt } \\
\text { Actien Gesellchaft }\end{array}$ \\
\hline Nelson Line & $\begin{array}{c}\text { Pacific Steam } \\
\text { Navigation Co. }\end{array}$ & Loyd Sabuado & $\begin{array}{c}\text { Compañía } \\
\text { Transatlántica } \\
\text { Española }\end{array}$ & \begin{tabular}{|c|} 
Hamburg- \\
Sudamericanische \\
Dampfschiffahrst \\
Gessells chatt \\
\end{tabular} \\
\hline $\begin{array}{l}\text { Royal Mail Steam } \\
\text { Packet Co }\end{array}$ & $\begin{array}{c}\text { Royal Mail Steam } \\
\text { Packet Co. }\end{array}$ & $\begin{array}{l}\text { Navigazone } \\
\text { Generale } \\
\text { Italiana } \\
\end{array}$ & $\begin{array}{l}\text { Royal mail Steam } \\
\text { Packet Co. }\end{array}$ & $\begin{array}{c}\text { Pacific Steam } \\
\text { Navigation Co. }\end{array}$ \\
\hline \begin{tabular}{|l} 
Pinillos Izquierdo \\
\end{tabular} & & La Veloce & & Chargeurs Reunis \\
\hline $\begin{array}{l}\text { Mesageries } \\
\text { Maritimes }\end{array}$ & \begin{tabular}{|c|} 
Hamburg- \\
Sudamericanische \\
Dampfschiffahrst \\
Gessells chatt \\
\end{tabular} & $\begin{array}{c}\text { Italia Societa di } \\
\text { Navegazone á } \\
\text { Vapore }\end{array}$ & $\begin{array}{c}\text { Hamburg- } \\
\text { Americanische } \\
\text { Packetfahrt Actien } \\
\text { Gesellchaft } \\
\end{array}$ & $\begin{array}{c}\text { Compañía } \\
\text { Transatlántica } \\
\text { Española }\end{array}$ \\
\hline $\begin{array}{l}\text { Norddeutscher } \\
\text { Lloyd }\end{array}$ & $\begin{array}{c}\text { British and South } \\
\text { American Steam } \\
\text { Navigation }\end{array}$ & Lloyd Italiana & \begin{tabular}{|c|} 
Hamburg- \\
Sudamericanische \\
Dampfschiffahrst \\
Gessells chatt \\
\end{tabular} & \\
\hline $\begin{array}{c}\text { Hamburg- } \\
\text { Americanische } \\
\text { Packetfahrt } \\
\text { Actien Gesellchaft }\end{array}$ & $\begin{array}{c}\text { Manuel María de } \\
\text { Arrotegui }\end{array}$ & $\begin{array}{l}\text { Compañía } \\
\text { Transatlántica } \\
\text { Española }\end{array}$ & $\begin{array}{c}\text { Pacific Steam } \\
\text { Navigation Co. }\end{array}$ & \\
\hline \begin{tabular}{|c|} 
Hamburg- \\
Sudamericanische \\
Dampfschiffahrst \\
Gessells chatt \\
\end{tabular} & \begin{tabular}{|c|} 
Hamburg- \\
Americanische \\
Packetfahrt \\
Actien Gesellchaft
\end{tabular} & La Veloce & $\begin{array}{c}\text { Manuel María de } \\
\text { Arrotegui }\end{array}$ & \\
\hline
\end{tabular}

y Gibraltar fueron puntos de salida de gallegos, vascos, andaluces y castellanos. Vázquez, Alejandro. "La salida», En Historia general de la emigración española a Iberoamérica, coord. Pedro A. Vives, Pepa Vega y Jesús Oyamburu (Madrid: CEDESAL, 1992), 248-255. 


\begin{tabular}{|c|c|c|c|c|}
\hline Vigo & Coruña & Barcelona & Santander & Bilbao \\
\hline $\begin{array}{c}\text { Sociedad Anónima } \\
\text { de Navegación } \\
\text { Trasatlántica }\end{array}$ & $\begin{array}{c}\text { Norddeutscher } \\
\text { Lloyd }\end{array}$ & & $\begin{array}{c}\text { Norddeutscher } \\
\text { Lloyd }\end{array}$ & \\
\hline $\begin{array}{c}\text { Boat Steam Ship } \\
\text { Co Ltd }\end{array}$ & Nelson Line & & & \\
\hline $\begin{array}{c}\text { Liverpool Brazil } \\
\text { River Plate Co. }\end{array}$ & $\begin{array}{c}\text { Genrale } \\
\text { Transatlantique }\end{array}$ & & & \\
\hline $\begin{array}{c}\text { Pacific Steam } \\
\text { Navigation Co. }\end{array}$ & $\begin{array}{c}\text { Koninlijke } \\
\text { Hollandsche Lloyd }\end{array}$ & & & \\
\hline $\begin{array}{c}\text { Koninlijke } \\
\text { Hollandsche Lloyd }\end{array}$ & $\begin{array}{c}\text { Transañía } \\
\text { Españolica }\end{array}$ & & & \\
\hline Chargeurs Reunis & $\begin{array}{c}\text { Argentine Cargo } \\
\text { Line Ltd. }\end{array}$ & & & \\
\hline $\begin{array}{c}\text { Generale } \\
\text { Transatlantique }\end{array}$ & & & & \\
\hline $\begin{array}{c}\text { Manuel María de } \\
\text { Arrotegui }\end{array}$ & & & & \\
\hline
\end{tabular}

Cuadro 3. Puertos de embarque y compañías navieras

Fuente: elaboración propia con base en Cartilla del Emigrante, pp. 25-27.

La información que ofrecía la Cartilla del emigrante, se complementaba con los costos que los potenciales viajeros pagarían al adquirir su pasaje de tercera clase en la Transatlántica Española, de acuerdo con el siguiente cuadro.

\begin{tabular}{|c|c|}
\hline Destino & Costo del viaje \\
\hline $\begin{array}{c}\text { Brasil, Uruguay, Argentina y } \\
\text { Nueva York }\end{array}$ & 150 a 200 pesetas \\
\hline $\begin{array}{c}\text { Venezuela, Colón, Sabanilla, } \\
\text { Costa Rica o Veracruz }\end{array}$ & 250 pesetas \\
\hline Puerto Rico & 200 pesetas \\
\hline Cuba & 625 pesetas \\
\hline $\begin{array}{c}\text { Punta Arenas de Costa Rica y a } \\
\text { los puertos de Colombia, menos } \\
\text { Sabanilla }\end{array}$ & 700 a 750 pesetas \\
\hline Nicaragua & 750 a 775 pesetas \\
\hline $\begin{array}{c}\text { Honduras, Salvador o } \\
\text { Guatemala }\end{array}$ & 725 a 800 pesetas \\
\hline Ecuador & Perú \\
\hline
\end{tabular}




\begin{tabular}{|c|c|}
\hline Destino & Costo del viaje \\
\hline $\begin{array}{c}\text { Chile y puertos en México, } \\
\text { excepto Veracruz y Tampico }\end{array}$ & 800 a 850 pesetas \\
\hline $\begin{array}{c}\text { San Francisco (Estados Unidos } \\
\text { de Norteamérica) }\end{array}$ & 925 pesetas \\
\hline
\end{tabular}

Cuadro 4. Tarifas en tercera clase en la Transatlántica Española

Fuente: Elaboración propia con base en el Cartilla del Emigrante, p. 28.

Resulta sugerente la información ofrecida por los autores, ya que a su juicio el perfil del viajero era el de un pasajero de tercera clase y por lo tanto realizaría un desembolso en la clase más económica. La puntualización hecha por Rízquez y Ordóñez a contraluz de la realidad del migrante, resulta un factor a destacar, ya que el jornal anual de un trabajador español-cuyo importe en términos generales se puede calcular en 1,75 pesetas diarias-, sobre todo de las áreas de mayor movilidad transatlántica, difícilmente le permitía cubrir el importe del boleto, por lo que habría que mencionar que la "cultura migratoria" se nutría de otros recursos económicos, a saber, préstamos, pasajes pagados por enganchadores de empresas de colonización y familiares que habían antecedidos a los migrantes en América, etc.; mecanismos que pondrían en entredicho la condición de pobreza del individuo que se aprestaba a «hacer la América» ${ }^{32}$.

La perspectiva médica, la salud, la condición física y la edad del emigrante también fueron aspectos que se consideraron en los planteamientos de los autores de la Cartilla, sobre todo del doctor Melchor Ordóñez, quien antes de la travesía recomendaba la consulta y el diagnóstico médico ${ }^{33}$. Sin lugar a duda, en la mente del galeno estaban presentes las medidas y restricciones higiénico-sanitarias que se habían

32 Entre los estudios que abordan los casos de catalanes, asturianos, gallegos y vascos véase César Yáñez Gallardo. Saltar con red. La temprana emigración catalana a América 1830-1870. (Madrid: Alianza Editorial, 1996; Rafael Anes. "La gran emigración asturiana», en Españoles hacia América..., 33-52; Alejandro Vázquez. «La emigración gallega. Migrantes, transporte y remesas», en Españoles hacia América..., 80-104; Emiliano Fernández de Pinedo. «Los movimientos migratorios vascos hacia América», en Españoles hacia América..., 105-122.

33 Rísquez Alfonso y Ordóñez, Cartilla del Emigrante..., 30-31. 
adoptado a partir de 1908 en varios países de América Latina, cuyo objetivo era impedir el acceso de individuos enfermos, viciosos, prostitutas, proxenetas, lisiados, entre otros. Otra de las recomendaciones que se hicieron estuvo relacionada con las precauciones que el viajero debería tener con el clima en el lugar de destino, el equipaje, recursos monetarios para atender sus primeros gastos y proveerse de un botiquín que le permitiera afrontar los primeros auxilios en caso de alguna contingencia. El doctor Ordóñez también alertó sobre los efectos del hacinamiento en los departamentos de tercera clase -que era la sección en la que la mayoría de los españoles viajaban al igual que los demás emigrantes europeos-, también señaló las condiciones y calidad que deberían tener el agua y los alimentos durante la travesía, así como el que se contara con servicio médico a bordo ${ }^{34}$.

Con el fin de que los potenciales emigrantes españoles no fueran presas de empresas navieras y agentes migratorios, de países en América que no cumplían en muchos casos con la oferta de servicios, los autores de la Cartilla, les informaban que contaban con el apoyo de varias instituciones ex profeso, como el Consejo de Emigración con sede en Madrid, que a su vez formaba parte del Ministerio de Gobernación, así como de las Juntas Locales e inspectores del ramo en distintos puertos de la Península; todo ello para evitar penalidades y abusos en la empresa migratoria. Con este propósito invitaban a los interesados a revisar la legislación española y americana en la materia, y a acudir al servicio consular acreditado en el exterior, para formalizar su registro y hacerse acreedores a todos los servicios y derechos como españoles. También se recomendaba a los migrantes que de ser necesario tras su arribo se instalaran en los Hoteles de Emigrantes, mientras ultimaban los detalles de su destino final en países como Argentina y Brasil, que brindaban este tipo de apoyo a los recién llegados que estuvieran inscritos en empresas de colonización ${ }^{35}$.

34 Rísquez Alfonso y Ordóñez, Cartilla del Emigrante..., 32-34.

35 Rísquez Alfonso y Ordóñez, Cartilla del Emigrante, 47-49. El establecimiento de Hoteles de inmigrantes fue parte de la política migratoria de algunos de los países que recibieron las cuotas más altas en el sur del continente americano. El alojamiento, 
La Cartilla del Emigrante enfatizó las potencialidades que ofrecían las condiciones físicas y los recursos naturales de las naciones del continente americano, que constituían el atractivo para laborar en los ámbitos agrícola, minero, mercantil, industrial, servicios, etc. En virtud a tal perspectiva, tanto Rísquez como Ordóñez puntualizaron la capacidad y especialización que los españoles de las diversas regiones de la Península presentaban, lo que les permitiría integrarse económicamente en los lugares que eligieran para establecerse, como lo hemos concentrado en el cuadro número cinco. Entre las recomendaciones que al efecto hicieron destacó la siguiente consideración, así como a tener presente una limitante que de ninguna manera deberían de ignorar:

[...] en todas las naciones de Hispano-América sobra donde ejecutar las aptitudes y la voluntad para el trabajo; allí puede decirse que toda ocupación tiene salario, y que, como países jóvenes y en el periodo de formación, el acomodo, la ganancia, el porvenir, dependen más de las condiciones particulares del emigrante que de las de aquellos países donde la tierra sobra, las poblaciones faltan, las industrias prosperan y la fortuna tiene galardones para el extranjero honrado y laborioso, para quien no hay en aquel paraíso sino un fruto prohibido; la política interior ${ }^{36}$.

\begin{tabular}{|c|c|}
\hline Procedencia regional & Especialidad laboral \\
\hline Catalanes & $\begin{array}{c}\text { Industriales, comerciantes, } \\
\text { artistas y agricultores }\end{array}$ \\
\hline Valencianos & $\begin{array}{c}\text { Hortelanos, artistas, } \\
\text { agricultores e industriales }\end{array}$ \\
\hline Andaluces & $\begin{array}{c}\text { Agricultores, ganaderos, } \\
\text { mineros e industriales }\end{array}$ \\
\hline
\end{tabular}

pago de primeros jornales, alimentación, instrucción y otras actividades fueron parte del primer contacto de los migrantes con el lugar de arribo; las limitaciones y carencias operativas no estuvieron exentas de este tipo de establecimientos, lo que de una u otra manera impacto negativamente en los recién llegados. Sobre el Hotel de Inmigrantes en Buenos Aires y Sao Paulo véase Laura Oliva Gerstner «Alojamiento de inmigrantes en el Río de la Plata, siglos XIX y XX: planificación estatal y redes sociales», Revista Bibliográfica de Geografía y Ciencias Sociales XIII, n 779 (2008); y Horacio Capel «El control de las migraciones internacionales y el memorial de inmigrantes en Sâo Paulo, Brasil», Revista Bibliográfica de Geografía y Ciencias Sociales XII, n 739 (2007).

36 Rísquez Alfonso y Ordóñez, Cartilla del Emigrante..., 45. 


\begin{tabular}{|c|c|}
\hline Procedencia regional & Especialidad laboral \\
\hline Extremeños & Ganaderos y agricultores \\
\hline Castellanos (Castilla la Nueva) & $\begin{array}{c}\text { Agricultores, industriales, } \\
\text { artistas y ganaderos }\end{array}$ \\
\hline Castellanos (Castilla la Vieja) & $\begin{array}{c}\text { Agricultores, mineros, } \\
\text { industriales y ganaderos }\end{array}$ \\
\hline Aragoneses & $\begin{array}{c}\text { Agricultores, industriales y } \\
\text { mineros }\end{array}$ \\
\hline Leoneses & $\begin{array}{c}\text { Agricultores, mineros, } \\
\text { ganaderos e industriales }\end{array}$ \\
\hline Asturianos y Gallegos & $\begin{array}{c}\text { Agricultores, mineros, } \\
\text { ganaderos, industriales, } \\
\text { artesanos y obreros }\end{array}$ \\
\hline Navarros & $\begin{array}{c}\text { Agricultores, mineros e } \\
\text { industriales }\end{array}$ \\
\hline Vizcaínos & $\begin{array}{c}\text { Agricultores, mineros e } \\
\text { industriales }\end{array}$ \\
\hline Vascongados & Agricultores, mineros e \\
& industriales \\
\hline Canarios & Agricultores e industriales \\
\hline Baleares & Agricultores e industriales \\
\hline
\end{tabular}

Cuadro 5. Perfil laboral y regional de los emigrantes españoles Fuente: elaboración propia con base en Cartilla del Emigrante, pp. 43-44.

De acuerdo con el cuadro anterior, se advierte que, conforme al criterio e información con la que dispusieron los autores de la Cartilla como fueron las estadísticas publicadas por el Instituto Geográfico y Estadístico, los españoles de las catorce regiones de origen eran individuos ligados a los sectores primario y terciario de la economía, con la salvedad de los catalanes, que además tenían como característica su participación en el ámbito mercantil; cifras que revelan que entre los emigrantes la mayoría eran hombres dedicados a actividades del sector primario, sobre todo a la agricultura ${ }^{37}$. Sin lugar a duda que para 1910, las referencias de la presencia

37 César Yáñez Gallardo, La emigración española a América..., 183-194. A los agricultores siguieron los comerciantes y transportistas, industriales, artesanos, profesiones liberales y sirvientes como lo puntualiza Yáñez Gallardo con los datos oficiales españoles. 
de los españoles en los países en que se habían instalado del otro lado del Atlántico, -en la que una minoría destacaba en los más variados rubros económicos-, había observado un giro en la formación ocupacional y adiestramiento cotidiano, pues era bien sabido el peso que tenían en el ámbito mercantil en todos sus rubros, que era un elemento distintivo del colectivo en general.

En el capítulo octavo de la Cartilla se hizo una sucinta presentación de todos los países de Hispano América. Entre los elementos informativos que se incorporaron destacaron datos alusivos a su composición geográfica, población, sistema de gobierno, economía, moneda, clima, recursos naturales, fauna, etc. Es de llamar la atención que los autores no hicieran mayor énfasis en la presencia de españoles en varias de las naciones del continente, sobre todo en virtud al papel que muchos desempeñaban en la economía y la sociedad, lo que sería la muestra fehaciente del grado de integración en los lugares de acogida ${ }^{38}$. De igual manera, lo anterior contrasta sustancialmente con la sugerente perspectiva y descripción que brindaban medios impresos de la época sobre las capitales de las repúblicas americanas -lugares hacia los que preferentemente se dirigían los migrantes-, como en distintos momentos lo hizo La Ilustración Española y Americana que se editaba en Madrid ${ }^{39}$.

La normativa migratoria española fue uno de los puntos centrales de la Cartilla, sobre todo se hizo énfasis en las disposiciones de los años de 1907 y 1908, como la Ley de emigración y su Reglamento, respectivamente. Para complementar lo estipulado por el país emisor, se agregaron datos sobre los lineamientos migratorios en vigor por parte de las naciones de acogida, como Argentina, Bolivia, Brasil, Costa Rica, Cuba, Chile, Guatemala, Perú, México, Uruguay y Venezuela. Con las puntualizaciones realizadas por los autores podemos advertir la importancia que esta cuestión

38 Rísquez Alfonso y Ordóñez, Cartilla del Emigrante..., 64-86.

39 Carmen Adams Fernández, La América distorsionada. Una visión española de fines del siglo XIX. (Oviedo: Universidad de Oviedo, 1999). En particular véase el capítulo VIII. 
revestía para los países receptores, así como las variantes y particularidades de cada uno de ellos, según la experiencia que tenían en materia de migración ${ }^{40}$.

Con la finalidad de mantener los nexos de los emigrantes españoles en América, los autores de la Cartilla propusieron la elaboración de un censo, iniciativa que coincidía con el ejercicio cuantitativo poblacional a nivel internacional que se realizaría en el año de 1910. Para tal efecto, se solicitó que llenaran hojas de registro en las que anotarían su experiencia en el proceso migratorio, es decir, desde el momento en que salieron de España, la situación que guardaban al momento del conteo y si eran contribuyentes en los países de residencia. También se les requirieron datos sobre los vínculos que mantenían con España y su familia, indicando si les prestaban algún auxilio, o bien, en su defecto lo recibe de aquella. Respecto al recuento en sí se les solicitaría que proporcionaran su nombre y apellidos, edad, estado civil, el pueblo y provincia de donde era originario, el tiempo de permanencia en América y su residencia actual y su profesión u oficio a que se dedicaban. Para el buen curso de esta empresa, la Unión Ibero-Americana invitaba a los emigrantes para que se acercaran a las legaciones diplomáticas para hacerles llegar la información ${ }^{41}$.

Por último, la Unión Ibero-Americana a través de la Cartilla hizo un llamado a los emigrantes españoles en América para que impulsaran la formación de sociedades que los representaran, ya que de esta manera se fortalecían los nexos y la unidad de sus integrantes y se fomentaría el amor a la patria. En este sentido se valoraban los esfuerzos que estas instituciones, la mayoría de ellas de carácter regional -sobre el particular podemos agregar que había otras de corte nacional, asistencial, mutualistas, beneficencia, esparcimiento, deportivas, etc. ${ }^{42}$, desempeñaban en la realización de

40 Rísquez Alfonso y Ordóñez, Cartilla del Emigrante..., 87-111.

41 Rísquez Alfonso y Ordóñez, Cartilla del Emigrante..., 112-115. Hasta el momento desconocemos si dicho ejercicio se llevó a efecto.

42 Alejandro Fernández. «Mutualismo y asociacionismo». En Historia general de la emigración española a Iberoamérica, coord. Pedro A. Vives, Pepa Vega y Jesús Oyamburu (Madrid: CEDESAL, 1992), 331-357. 
círculos sociales y la edición de publicaciones periódicas que daban cuenta de sus labores, tal y como se efectuaban en las ciudades de México, La Habana, Caracas, Buenos Aires, así como en otros centros urbanos ${ }^{43}$. Esta experiencia colectiva contaba con una notoria trayectoria que databa de mediados del siglo XIX; esfuerzo comunitario que alcanzaría sus cuotas más altas en los primeros años de la década de $1920^{44}$. En resumidas cuentas, los migrantes españoles eran el elemento vivo y cotidiano del hispanismo en los países de América ${ }^{45}$.

\section{Conclusiones}

Desde su creación, la Unión Ibero-Americana se proyectó como uno de los pilares del hispanismo fuera de España. Si bien las actividades de la Unión se enmarcaban en un amplio escenario cultural, su influencia también comprendió la economía y la política, entre otros, gracias a la labor que emprendieron sus socios tanto en su calidad de hombres de Estado como de connotados empresarios, académicos y filántropos, ya que buscaron a toda costa mantener la presencia de España en el ámbito internacional, cuyo radio de acción natural abarcó a los países del continente americano, en los que contaba con varios centros similares y corresponsalías.

En el marco de los festejos del primer centenario de la independencia de las naciones de América Latina, la Unión planteó su participación considerando la creciente movilidad de peninsulares en muchos de esos países, impulsados por las condiciones económicas, políticas y sociales que imperaron en España a lo largo del siglo XIX, y que justo en esos momentos estaba por alcanzar sus índices más altos en los primeros años de la década de 1910, siguiendo indistintamente los cauces

43 Rísquez Alfonso y Ordóñez, Cartilla del Emigrante..., 116.

44 Moisés Llorens Miñambres, «Las asociaciones de inmigrantes españoles en América. Algunas respuestas a los desequilibrios y carencias de la emigración a ultramar», en Exils et migrations iberiques vers Amérique latine, coord. Pilar González Bernaldo et Fernando Devoto (París, Publications universitares DenisDiderot, 1998), 79-130. Sobre el ámbito de la letra impresa véase Pablo Mora y Ángel Miquel, Españoles en el periodismo mexicano siglos XIX y XX (México: Universidad Autónoma de Morelos/UNAM, 2008).

45 Isidro Sepúlveda, El sueño de la Madre Patria..., 363-408. 
legales y los proscritos. La formalización de esta iniciativa se materializó en la Cartilla del Emigrante, cuyo contenido no solo era la expresión de sus autores, sino la voz de la Unión Iberoamericana misma.

De esta manera se pretendía encausar de la mejor forma el flujo migratorio español a esas latitudes, sobre todo siguiendo las disposiciones legales en la materia que comprendían tanto las normas legislativas sancionadas en el lugar de origen como las de destino. El cumplimiento de estos procedimientos permitiría un mayor control de entradas y salidas en ambos lados del Atlántico, así como su localización. El carácter informativo y preventivo que estaba presente en la Cartilla del emigrante definía un nuevo perfil del viajero, ya que se le recomendaba la atención médica previo el embarque. No menos importante era el orientarlo sobre los servicios y costos del medio de transporte, así como de las condiciones físicas y los recursos naturales de la mayoría de los países de América Latina, lo que se complementó con la recomendación del trabajo constante y los beneficios que ello le reportaría. En el mejor de los casos podemos advertir que la Unión Ibero Americana promovía una migración concienciada que permitiera a los migrantes que su opción de vida en el otro lado del Atlántico se inscribiera dentro de las mejores condiciones posibles, ya que del bienestar alcanzado y su éxito se dejaría sentir en los lugares de donde habían partido.

\section{Bibliografía}

$A B C$, Madrid, 11 febrero 1910.

Adams Fernández, Carmen. La América distorsionada. Una visión española de fines del siglo XIX, Oviedo: Universidad de Oviedo, 1999.

Anes, Rafael. "La gran emigración asturiana». En Españoles hacia América. La emigración en masa, 1880-1930, compilado por Nicolás Sánchez Albornoz. Madrid: Alianza Editorial, 1995.

Bade, Klaus J. Europa en movimiento. Las migraciones desde fines del siglo XVIII hasta nuestros días. Barcelona: Crítica, 2003. 
Bahamonde, Ángel. «Los dos lados de la emigración transoceánica». En Historia general de la emigración española a Iberoamérica, coordinado por Pedro A. Vives, Pepa Vega y Jesús Oyamburu. Madrid: CEDESAL, 1992.

Capel, Horacio. "El control de las migraciones internacionales y el memorial de inmigrantes en Sâo Paulo, Brasil», Revista Bibliográfica de Geografía y Ciencias Sociales XII, nº 739 (2007).

Compilación de las disposiciones dictadas sobre emigración. Madrid: Inspección General de Emigración, Imprenta Sáenz Hermanos, 1933.

Dobado, Rafael., Aurora Gómez Galvarriato y Gabriela Márquez, comps. México y España. ¿Historias económicas paralelas? (Lecturas 98), México: Fondo de Cultura Económica, 2007.

Fernández, Alejandro. «Mutualismo y asociacionismo». En Historia general de la emigración española a Iberoamérica, coordinado por Pedro A. Vives, Pepa Vega y Jesús Oyamburu. Madrid: CEDESAL, 1992.

Fernández de Pinedo, Emiliano. «Los movimientos migratorios vascos en especial hacia América». En Españoles hacia América. La emigración en masa, 1880-1930, coordinado por Pedro A. Vives, Pepa Vega y Jesús Oyamburu. Madrid: Alianza Editorial, 1995.

García-Montón G.-Baquero, Isabel. «El Congreso Social y Económico Hispanoamericano de 1900: un instrumento del hispanoamericanismo modernizador». Revista Complutense de Historia de América, nº 25 (1999): 281-294.

Gerstner, Laura Olivia. «El alojamiento de inmigrantes en el Río de la Plata, siflos XIX y XX: planificación estatal y redes sociales». Revista Bibliográfica de Geografía y Ciencias Sociales XIII, n 739 (2008).

González, Elda E. «La llegada». En Historia general de la emigración española a Iberoamérica, coordinado por Pedro A. Vives, Pepa Vega y Jesús Oyamburu. Madrid: CEDESAL, 1992. 
Ilustre Colegio Oficial de Titulados Mercantiles y Empresariales de Santa Cruz de Tenerife. «El Colegio. Presidente. Melchor Ordóñez Alonso». Acceso el 28 de septiembre de 2013, http:// www.cotime.es/el-colegio/presidentes/249-melchorordoñezalonso.htm.

Klein, Herbert. La inmigración española en Brasil, Gijón: Fundación Archivo de Indianos, Ministerio de Asuntos Sociales/Dirección General de Migraciones, 1996.

Livi Bacci, Máximo. Historia de la población europea. Barcelona: Crítica, 1999.

Llorens Miñambres, Moisés. "Las asociaciones de inmigrantes españoles en américa. Algunas respuestas a los desequilibrios y carencias de la emigración a ultramar». En Exils et migrations ibériques vers l'Amérique latine, coordinado por Pilar González Bernaldo et Fernando Devoto. París: Publications Universitaries Denis Diderot, 1998.

Martín Montalvo, C., Ma. Rosa Martín de la Vega y Ma. Teresa Solano Sobrado, «El hispanoamericanismo, 1880-1930». Quinto Centenario 8 (1985): 149-164.

Mora, Pablo., y Ángel Miquel, comp. y ed. Españoles en el periodismo mexicano siglos XIX y XX. México: Universidad Autónoma de Morelos/UNAM, 2008.

Moya, José C. Cousins and strangers. Spanish inmigrantes en Buenos Aires, 1850-1930. Los Angeles: University of California Press, 1998.

Pérez Prendes y Muñoz de Arraco, José Manuel. El marco legal de la emigración española en el Constitucionalismo. Gijón: Fundación Archivo de Indianos, 1993.

Rama, Carlos M. Historia de las relaciones culturales entre España y la América Latina. Siglo XIX. México: Fondo de Cultura Económica, 1982.

Rajo Serventich, Alfredo. "Las dimensiones del hispanismo e hispanoamericanismo». Latinoamérica, nº 47 (2008): 97-116. 
Rísquez Alfonso, Jesús María., y Melchor Ordóñez. Cartilla del Emigrante, Madrid: Imprenta de los Hijos de M. G. Hernández, 1910.

Rodríguez, Miguel. Celebración de «laraza». Unahistoriacomparativa del 12 de octubre. México: Universidad Iberoamericana, 2004.

Sánchez Albornoz, Nicolás., comp. Españoles hacia América. La emigración en masa, 1880-1930. Madrid: Alianza Editorial, 1995.

Sánchez Alonso, Blanca. Las causas de la emigración española 18801930. Madrid: Alianza Editorial, 1995.

Sánchez Alonso, Blanca. «La emigración española a la Argentina, 1880-1930». En Españoles hacia América. La emigración en masa, 1880-1930, compilado por Nicolás Sánchez Albornoz. Madrid: Alianza Editorial, 1995.

Sánchez Alonso, Blanca. Los mitos de la emigración española. Madrid: Universidad CEU San Pablo, 2015.

Santos, Ricardo Evaristo. Política migratoria española a Iberoamérica: aporte Brasil, 1890-1950. La Coruña: Edicios do Castro, 1996.

Sepúlveda, Isidro. El sueño de la Madre Patria. Hispanismo $y$ nacionalismo. Madrid: Fundación Carolina/Centro de Estudios Hispánicos e Iberoamericanos/Marcial Pons, 2005.

Souza Martins, José de. "La inmigración española en Brasil y la formación de la fuerza de trabajo en la economía cafetalera, 1880-1930». En Españoles hacia América. La emigración en masa, 1880-1930, compilado por Nicolás Sánchez Albornoz. Madrid: Alianza Editorial, 1995.

Unión Ibero-Americana. Estatutos y Reglamento aprobados en Junta General el 25 de enero de 1885, y el 5 de febrero por la autoridad competente. Madrid: Imprenta de Moreno y Rojas, 1885.

Unión Ibero-Americana. Estatutos y reglamento reformados en Junta General extraordinaria de los días 15 y 16 de enero de 1886, y 
aprobados por la autoridad competente en 28 del mismo mes y año. Memorial anual, estado económico, Consejo de Gobierno y Junta Directiva, lista de socios protectores, de mérito y de número, de adheridos. Madrid: Imprenta de Alfonso Rodero, 1886.

Vázquez, Alejandro. «La salida». En Historia general de la emigración española a Iberoamérica, coordinado por Pedro A. Vives, Pepa Vega y Jesús Oyamburu. Madrid: CEDESAL, 1992.

Vázquez, Alejandro. «La emigración gallega. Migrantes, transporte y remesas». En Españoles hacia América. La emigración en masa, 1880-1930, compilado por Nicolás Sánchez Albornoz. Madrid: Alianza Editorial, 1995.

Yáñez Gallardo, César. La emigración española a América (siglos XIX y XX). Gijón: Principado de Asturias, Archivo de Indianos, Caja de Asturias, 1994.

Yáñez Gallardo, César. Saltar con red. La temprana emigración catalana a América 1830-1870. Madrid: Alianza Editorial, 1996.

\section{Citar este artículo:}

Pérez Acevedo, Martín. «Migración española hacia América desde la perspectiva de la Cartilla del Emigrante (1910)». Historia Y MEMORIA, $\mathrm{n}^{\circ} 15$ (2017): 169-201. DOI: https://doi. org/10.19053/20275137.n15.2017.5594 